pathogens. The range used included strains of Sonne, Flexner, Newcastle, Shiga, coli, typhoid and cholera. We have always found Sonne strains to be the most resistant to sulphanilylguanidine and Shiga and typhoid strains somewhat resistant, while sulphanilylbenzamide has proved highly potent in all types. The mouse test referred to above is one suggested by Marshall2. It is based on the reduction in the concentration of the lactose-fermenting organisms in the fresh stools of mice fed on a diet containing 2 per cent of the drugs. Fresh fæces are made into an emulsion containing approximately $50 \mathrm{mgm}$. in $5 \mathrm{ml}$. of broth and graded dilutions made on desoxycholate agar plates. The lactose-fermenting organisms are counted after twenty-four hours. Under these conditions sulphanilylbenzamide is as efficient as sulphanilylguanidine.

Whether the promising in vitro results, especially against Sonne, Shiga and typhoid types, are reproducible in man will in turn depend on whether the more rapid absorption of sulphanilylbenzamide from the gut is significant. Arrangements for such a clinical trial are being made.

It is hoped to publish a detailed account of this work elsewhere.

We have to thank Mr. T. Dewing of the Wellcome Chemical Works, Dartford, for kindly supplying sulphanilylbenzamide and Mr. W. H. Gray of the Wellcome Chemical Research Laboratories for kindly supplying $4: 4^{\prime}$-bis- $\gamma$-phenyl-n-propylaminodiphenylsulphone tetrasodium sulphonate.

Pharmacology Department,

GEORGE BROWNLEE. ISABEL M. TONKIN.

Wellcome Physiological Research Laboratories, Beckenham, Kent. July 18.

"Buttle, Dewing, Foster, Gray, Smith, and Stephenson, Biochem. J., 32, 1101 (1938).

'Marshall, Bratton, White, and Litchfleld, Bull. Johns Hopkins Hosp., 67, $163(1940)$.

: Marshall, Bratton, Edwards, and Walker, Bull. Johns Hopkins Hosp., 63, 94 (1941)

\section{Latero-sensory Canals and Dermal Bones}

J. A. Moy-Thomas ${ }^{1}$ has recently made important observations on the developmental relationship between the frontal bones and the supraorbital laterosensory canal in Salmo, and clearly considers that his experiments go far to destroy the whole basis of the homologization of dermal bones in fishes by reference to the latero-sensory system. His results are quite in harmony with, for example, Kindred's embryological study of Amiurus ${ }^{2}$, and no doubt somewhat similar conditions occur widely in teleosts, where the dermal bones of the skull-roof, particùlarly the frontals, play an important part in the mechanical structure of the cranium.

It is true that some workers have carried the use of the latero-sensory too far, especially where originally enclosed canals show a phylogenetic 'degeneration' to pit-lines, and I have several times ${ }^{3,4,5,6}$ noted necessary modifications to some of these rigid schemes. Nevertheless, in certain primitive fossil forms, and in the development of Amia (Pehrson"), there is abundant and convincing morphological evidence of a close developmental connexion between certain dermal bones and the latero-sensory system (excluding pitlines). In the most primitive known Actinopterygii,
Crossopterygii and Dipnoi the adult dermal skullroof consisted of bony plates, occupying the whole thickness of the corium, but having no part in the mechanical construction of the cranium; somewhat similar conditions still hold in Amia. But in most teleosts (Actinopterygii) and in all but the most primitive tetrapods (from Crossopterygii), several of the dermal bones have new functions as mechanically important cranial elements, and may become deepseated. It is precisely in these forms that the importance of latero-sensory canals as 'markers' of dermal bones is so greatly reduced. I am therefore unable to accept all Moy-Thomas's conclusions. His experiments should be repeated on Amia before such deductions can be drawn with confidence.

Moy-Thomas's findings are not unexpected. The early Crossopterygii, and probably the earliest tetrapods, are generally considered to show a close relationship between some of the dermal bones and laterosensory canals; but in higher tetrapods laterosensory canals fail to develop, and dermal bones such as the frontals form part of the mechanical structure of the skull. What seems to have been, in primitive forms, a simple 'secondary organizer' relationship involving early formed latero-sensory structures and certain later developed dermal bones, is replaced in tetrapods by apparently more complicated processes, in which the more integrated architecture of the cranium is clearly an important factor. The same may prove to be true of many Teleostei, and it seems likely that a programme of experiments like those of Moy-Thomas, applied to a large series of teleosts and to Amia, Lepidosteus and sturgeons, would provide valuable evidence in the important problem of the changes in organizer-reactions involved in the gradual modification of phylogenetically archaic structures to meet new needs.

Dept. of Geology and Mineralogy,

T. Stanley Westolt. University of Aberdeen. July 16.

1 NAture, 147, 681 (1941).

2 Illinois Biol. Monog., 5, No. 1 (1919).

J. Anat., 71, 362, esp. 378-80.

4 Ann, Mag. Nat. Hist., [10], 19, 553, esp. 571-72.

${ }^{5}$ Geot. Mag., 74, 507, esp. 517-20.

- Geol. Mag., 77, 65, esp. 72-73.

? Acta Zool., 3, 1.

\section{Function of the Ventral Tube in Onychiurus armatus (Collembola)}

Very little is known about the function of the ventral tube of Collembola. Until recently it has been regarded as an adhesive organ, but the observations of W. M. Davies ${ }^{1}$ suggest that in Sminthurus viridis (Linn.) at least, it may be used for eleansing the body and as a means of transferring drops of water from the surface of the body to the mouth where they are then absorbed. In connexion with this, Davies has suggested that 'free water' is essential for the survival of this species, even in a watersaturated atmosphere.

It is interesting, therefore, to record some results obtained with the soil-living Collembola, Onychiurus armatus (Tullb) under various culture conditions.

Onychiurus armatus has been maintained on Mucor cultures on agar media in Petri dishes where it moved freely over the vertical and horizontal surfaces without using the ventral tube vesicles. When placed on vital stains in various humidities the stain was 